\title{
Genome wide transcriptomic analysis of the soil ammonia oxidizing archaeon Nitrososphaera viennensis upon exposure to copper limitation
}

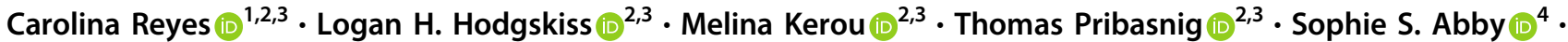 \\ Barbara Bayer $\mathbb{D}^{3,5,6} \cdot$ Stephan M. Kraemer ${ }^{1,3} \cdot$ Christa Schleper $^{2,3}$
}

Received: 28 February 2020 / Revised: 9 June 2020 / Accepted: 2 July 2020 / Published online: 14 July 2020

(c) The Author(s) 2020. This article is published with open access

\begin{abstract}
Ammonia-oxidizing archaea (AOA) are widespread in nature and are involved in nitrification, an essential process in the global nitrogen cycle. The enzymes for ammonia oxidation and electron transport rely heavily on copper $(\mathrm{Cu})$, which can be limited in nature. In this study the model soil archaeon Nitrososphaera viennensis was investigated via transcriptomic analysis to gain insight regarding possible $\mathrm{Cu}$ uptake mechanisms and compensation strategies when $\mathrm{Cu}$ becomes limiting. Upon $\mathrm{Cu}$ limitation, $N$. viennensis exhibited impaired nitrite production and thus growth, which was paralleled by downregulation of ammonia oxidation, electron transport, carbon fixation, nucleotide, and lipid biosynthesis pathway genes. Under Cu-limitation, 1547 out of 3180 detected genes were differentially expressed, with 784 genes upregulated and 763 downregulated. The most highly upregulated genes encoded proteins with a possible role in $\mathrm{Cu}$ binding and uptake, such as the $\mathrm{Cu}$ chelator and transporter CopC/D, disulfide bond oxidoreductase $\mathrm{D}(d s b D)$, and multicopper oxidases. While this response differs from the marine strain Nitrosopumilus maritimus, conserved sequence motifs in some of the Cu-responsive genes suggest conserved transcriptional regulation in terrestrial AOA. This study provides possible gene regulation and energy conservation mechanisms linked to $\mathrm{Cu}$ bioavailability and presents the first model for $\mathrm{Cu}$ uptake by a soil AOA.
\end{abstract}

\section{Introduction}

Ammonia-oxidizing archaea (AOA) perform the first and rate-limiting step of nitrification along with ammonia-

These authors contributed equally: Carolina Reyes, Logan H. Hodgskiss

Supplementary information The online version of this article (https:// doi.org/10.1038/s41396-020-0715-2) contains supplementary material, which is available to authorized users.

Carolina Reyes

creyes6@gmail.com

$\triangle$ Christa Schleper

christa.schleper@univie.ac.at

1 Department of Environmental Geosciences, Centre for Microbiology and Environmental Systems Science, University of Vienna, Althanstrasse 14, UZA2, 1090 Vienna, Austria

2 Department of Functional and Evolutionary Ecology, Archaea Biology and Ecogenomics Unit, University of Vienna, Althanstrasse 14, UZA1, 1090 Vienna, Austria oxidizing bacteria (AOB) and comammox [1-3]. AOA are ubiquitous and abundant in most aerobic environments $[4,5]$. Cultivated AOA strains belonging to the class Nitrososphaeria of the phylum Thaumarchaeota [6] represent some but not all of the currently recognized lineages of AOA based on environmental gene sequences [7].

A common feature of AOA is the central role of copper $(\mathrm{Cu})$ in their metabolism. Copper is used as a cofactor to many key proteins in AOA including the ammonia monooxygenase (AMO), which performs the energy-gaining step

3 Environmental Science Research Network (ESRN), Faculty for Geosciences, Geography and Astronomy, University of Vienna, Althanstrasse 14, UZA2, 1090 Vienna, Austria

4 University Grenoble Alpes, CNRS, Grenoble INP, TIMC-IMAG, 38000 Grenoble, France

5 Department of Limnology and Oceanography, Division of Biooceanography, University of Vienna, Althanstrasse 14, UZA1, 1090 Vienna, Austria

6 Present address: Department of Ecology, Evolution and Marine Biology, University of California Santa Barbara, Santa Barbara, CA 93106-9620, USA 
of ammonia oxidation, plastocyanins, which are encoded in high numbers by AOA and used presumably as electron carriers, and multicopper oxidases, whose role although conserved in AOA remains unclear [8, 9]. While the AMO of $\mathrm{AOB}$ also uses $\mathrm{Cu}$ as a cofactor, mostly heme-containing proteins such as hydroxylamine oxidoreductase (HAO) and cytochrome $\mathrm{C}_{\mathrm{M}} 552$ ( $\mathrm{CycB}$ ) make up the bacterial ammonia oxidation electron transport chain [10]. AOA, in contrast, lack homologs for both $\mathrm{HAO}$ and $\mathrm{CycB}$. The enzyme replacing $\mathrm{HAO}$ in $\mathrm{AOA}$ has yet to be determined, while $\mathrm{Cu}$ containing plastocyanins are hypothesized to act as electron carriers in place of $\mathrm{CycB}$ [8]. Therefore, AOA should depend more highly on $\mathrm{Cu}$ containing enzymes than their bacterial counterparts, which would necessitate elaborate regulatory mechanisms to respond to rapidly changing local concentrations of this metal. Indeed, the marine AOA Nitrosopumilus maritimus SCM1, with $\mathrm{Cu}$ adsorbed on its surface, exhibited exothermic enthalpies in contrast to neutral or endothermic enthalpies for AOB, suggesting a higher surface selectivity of AOA for $\mathrm{Cu}$ [11].

The abundance of $\mathrm{Cu}$ in the Earth's crust is significantly lower than that of other biologically important metals [12]. In terrestrial environments, its bioavailability is influenced primarily by organic matter content and $\mathrm{pH}$ [13]. Recently, Gwak et al. [14] showed that mixtures of organic compounds like yeast extract depleted $\mathrm{Cu}$ in culture experiments with AOA and AOB. However, only AOA growth was inhibited by reduced $\mathrm{Cu}$ bioavailability. These results support the idea that $\mathrm{Cu}$ is a more important trace element for AOA than AOB.

While the mechanisms by which different AOA clades take up $\mathrm{Cu}$ from their environment are not well understood, genomic analysis of the transporter complement of six different AOA, including the soil archaeon Nitrososphaera viennensis (EN76) [15, 16], showed that orthologs of multicopper oxidases and ZIP family permeases are conserved among AOA and could have a role in making $\mathrm{Cu}$ more bio-available and in $\mathrm{Cu}$ uptake respectively [9]. In addition, all known AOA harbor proteins belonging to the copper resistance CopC and CopD families, typically involved in $\mathrm{Cu}$ resistance mechanisms [17-20]. In general, Cop proteins are suggested to import $\mathrm{Cu}$ into cells [21, 22], to export $\mathrm{Cu}$ out of cells [23], and to bind $\mathrm{Cu}$ in the periplasm [24].

The effects of Cu-limitation on cell physiology, metabolism, and uptake have been studied on pure cultures of N. maritimus SCM1 [25, 26] and N. viennensis (EN76) [13]. These studies support the idea that $\mathrm{Cu}$ is essential for AOA and show that as $\mathrm{Cu}$ concentration becomes limiting, ammonia oxidation activity and cell growth decrease. While Qin et al. [26] provides a first outline to the $\mathrm{Cu}$ limitation transcriptomic response in marine AOA, the corresponding mechanisms in terrestrial lineages remain unexplored. Terrestrial AOA generally have larger genomes that have evolved under different selection pressures and exhibit different capabilities than the streamlined marine AOA [9].

The aim of this study was to identify genes potentially involved in $\mathrm{Cu}$-uptake and to identify physiological and regulatory responses in $N$. viennensis under $\mathrm{Cu}$-limiting conditions. As such, a genome-wide transcriptomic analysis of $N$. viennensis in response to $\mathrm{Cu}$-limiting conditions was performed and is presented along with supporting proteomic and quantitative PCR results. While the reaction of $N$. viennensis markedly differs from that of $N$. maritimus with respect to possible $\mathrm{Cu}$-sequestration, conserved regulatory motifs in downregulated genes show conservation among related soil strains.

\section{Methods}

Detailed cultivation procedures, measurement of ammonia oxidation, RNA extraction, protein extraction, quantitative reverse transcription PCR (RT-qPCR), sequencing methods, sequencing analysis, proteomic methods and analysis, motif analysis, and phylogenetic analysis are described in the Supplementary material.

\section{Cu-limiting conditions for differential gene expression}

The $\mathrm{Cu}$ chelator TETA (1,4,8,11-tetraazacyclotetradecane $\mathrm{N}, \mathrm{N}^{\prime}, \mathrm{N}^{\prime \prime}, \mathrm{N}^{\prime \prime \prime}$-tetraacetic acid hydrochloride hydrate) with selective affinity for $\mathrm{Cu}^{2+}$ was used to induce $\mathrm{Cu}$ limitation as previously described [13]. Five replicate $500 \mathrm{~mL}$ cultures were each inoculated either with a $\mathrm{Cu}$-limited $(\mathrm{Cu} 12)$ or a standard $N$. viennensis culture to establish $\mathrm{Cu}$-limited and $\mathrm{Cu}$-replete cultures respectively. It was estimated using the PhreeqC program [27] that $\mathrm{Cu}$-limited cultures $\mathrm{Cu} 10$ and Cu12 contained $6 \times 10^{-15} \mathrm{~mol} / \mathrm{L}$ and $8 \times 10^{-16} \mathrm{~mol} / \mathrm{L}$ of bioavailable $\mathrm{Cu}^{2+}$, respectively [13].

\section{RNA and proteome analysis}

Five replicate cultures of each growth condition of $N$. viennensis were harvested by filtration followed by extraction of RNA from the filters. Extracted RNA (cDNA) of each sample was sequenced by the Vienna Biocenter Facility [VCBF], Vienna, Austria, using an Illumina HiSeq2500 instrument. Raw read files were processed and then analyzed for differential expression using DESeq2 [28]. The Benjamini Hochberg DESeq2 default step was used to control for false discovery rate (FDR). Genes with an adjusted $p$ value $(p$-adj) $<0.01$ were considered differentially expressed. 


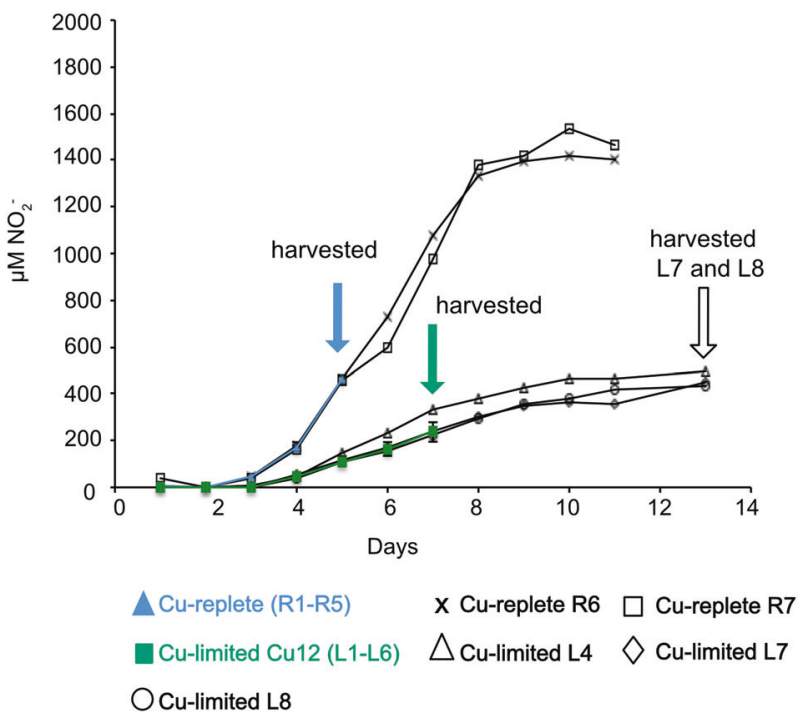

Fig. 1 Nitrite concentrations in batch cultures of $N$. viennensis grown in $500 \mathrm{~mL}$ in $1 \mathrm{~L}$ polystyrene bottles under $\mathrm{Cu}$-replete and Cu-limited (Cu12) conditions. Cu replete cultures, labeled (R1-R5) refer to the five biological replicates R1, R2, R3, R4, and R5 that were harvested on day 5. Cu limited cultures, labeled (L1-L3, L5-L6) refer to the five biological replicates as L1, L2, L3, L5, and L6 that were harvested on day 7. Solid arrows indicate when cultures were harvested for RNA extraction. Open arrow indicates when cultures were harvested for protein extraction. The data and error bars for $\mathrm{Cu}$-replete and $\mathrm{Cu}$-limited cultures represent the average and standard deviation of biological replicates.

Proteomic and RT-qPCR analyses were performed on two additional $\mathrm{Cu}$-limited cultures (L7 and L8) that were harvested on Day 13 (Fig. 1). While the proteomes from two $\mathrm{Cu}$-limited cultures verified the presence of multicopper oxidases, further critical analysis of the proteomic data was not carried out due to the lack of more biological replicates and the lack of proteome data from the control cultures.

All raw sequence runs from the RNA-Seq analysis were deposited in the DNA Databank of Japan (DDBJ) under the accession number DRA008627. The mass spectrometry proteomics data have been deposited to the ProteomeXchange Consortium via the PRIDE [29] partner repository with the dataset identifier PXD018461 and 10.6019/ PXD018461.

\section{Results and discussion}

\section{Growth response under $\mathrm{Cu}$-limiting conditions}

Initial growth tests with $N$. viennensis were performed in the presence and absence of TETA in order to determine if this $\mathrm{Cu}$ chelator affects growth of the organism. TETA alone did not have a toxic effect on cell growth, as cultures supplemented with TETA and excess $\mathrm{Cu}$ produced nitrite concentrations comparable to the $\mathrm{Cu}$-replete cultures (Fig. S1). When TETA was applied to $\mathrm{Cu}$-limited cultures, a decreased ability to oxidize ammonia compared to $\mathrm{Cu}-$ replete cultures was observed, while re-introduction of $\mathrm{Cu}$ to $\mathrm{Cu}$-limited $(\mathrm{Cu} 10)$ cultures restored their ability to produce nitrite comparable to the $\mathrm{Cu}$-replete culture (Fig. S1) [13]. These results demonstrate that TETA can be used to chelate $\mathrm{Cu}$ and induce $\mathrm{Cu}$-limitation in $N$. viennensis and that $\mathrm{Cu}$-limited cells retain the ability to oxidize ammonia following $\mathrm{Cu}$ addition. Metabolic recovery following $\mathrm{Cu}$ starvation has also been observed in studies with $N$. maritimus [25], where cells that were starved of $\mathrm{Cu}$ for up to 6 days recovered within $24 \mathrm{~h}$ of $\mathrm{Cu}$ addition.

For the transcriptome analyses, under $\mathrm{Cu}$-limiting versus $\mathrm{Cu}$-replete conditions, five replicates each were grown in parallel. At the time cultures were harvested for RNA extraction, Cu-replete cultures had produced 436-493 $\mu \mathrm{M}$ nitrite and $\mathrm{Cu}$-limited (Cu12) cultures had produced 202-334 $\mu \mathrm{M}$ nitrite (Fig. 1).

\section{RNA sequencing analysis}

RNA sequencing results are reported in Table S1. To analyse variation in gene expression between $\mathrm{Cu}$-replete and $\mathrm{Cu}$-limited conditions and between replicates of each condition a PCA analysis was performed. PCA results showed that the five replicates of each condition grouped together (Fig. S2) thus demonstrating high reproducibility. One principle component (PC1) could explain $\sim 51 \%$ of the variance between the $\mathrm{Cu}$-limited and $\mathrm{Cu}$-replete cultures. Comparison of protein-coding genes between $\mathrm{Cu}$-limited and $\mathrm{Cu}$-replete samples resulted in 1,547 differentially expressed genes out of 3,180 genes identified from reads mapped to the genome (Dataset S1) (Benjamini Hochberg adjusted $p$ value cut-off of 0.01). After careful evaluation of the data a $p$ value cut-off of 0.01 was chosen instead of the more commonly used 0.05 to define deferentially expressed genes, which allowed for a better focus of the results of the DESEq2 analysis. Because of the low adjusted $p$ values and therefore high statistical reproducibility, genes meeting this criteria were considered even if they showed small changes (in terms of the $\log _{2}$ fold change) between the two conditions. This is in line with previous archaeal studies that have identified and/or observed genes of physiological significance with a focus on a $p$ value cut-off irrespective of the $\operatorname{low} \log _{2}$ fold changes [30, 31]. Of the differentially expressed genes, 784 were upregulated $(24.7 \%$ of detected genes) and 763 were downregulated $(24.0 \%$ of detected genes) in $\mathrm{Cu}$-limited cultures. Overall, these results showed that $50 \%$ of the differentially expressed genes were upregulated in response to $\mathrm{Cu}$-limitation compared to $30 \%$ of genes upregulated in $\mathrm{Cu}$-limited $N$. maritimus cultures [26]. Next, to gain insight into the general biological function of 


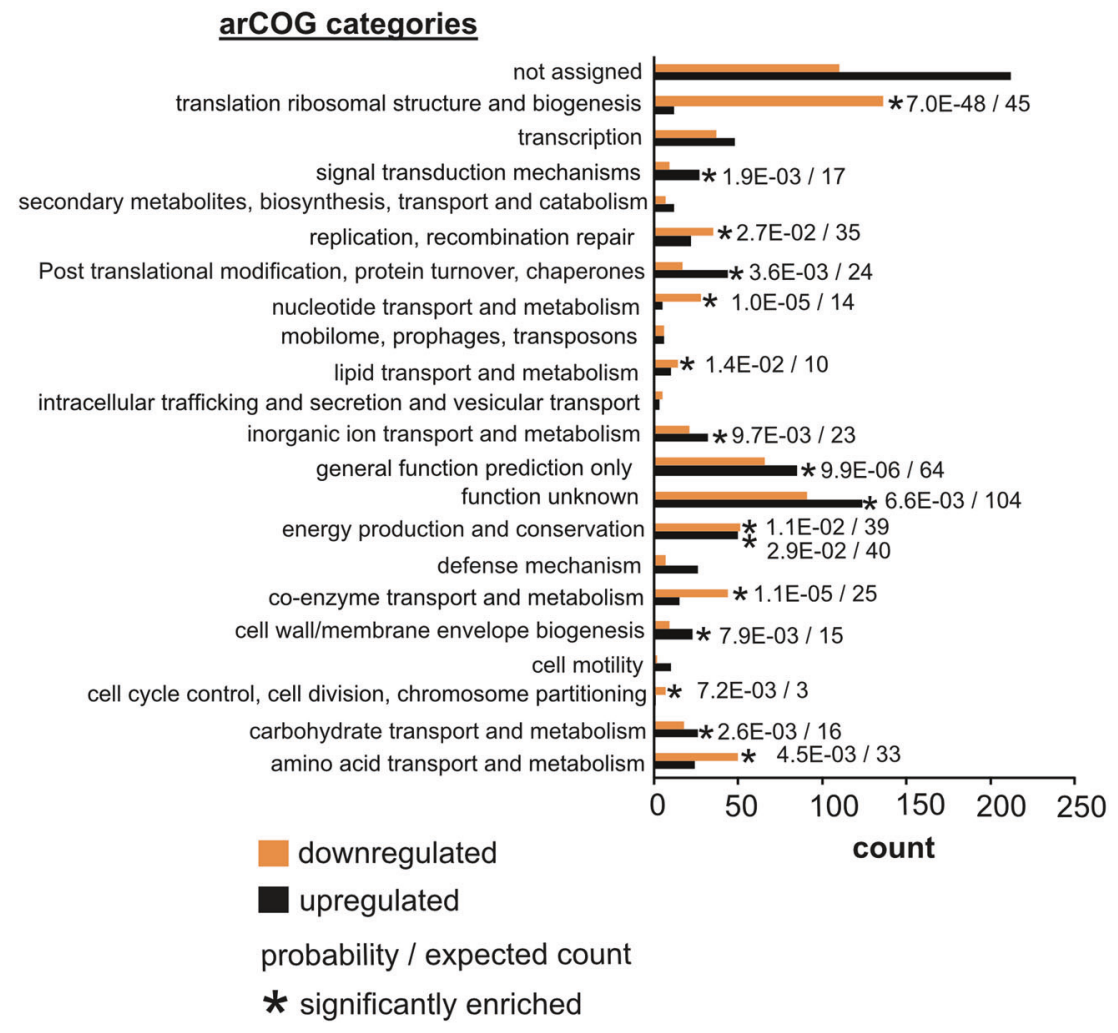

Fig. 2 Bar charts showing up and downregulated genes assigned to functional groups in $\mathrm{Cu}$-limited samples. Genes were assigned to functional categories based on their archaeal clusters of orthologous group (arCOG) categories. A $p$ value $<0.05$ cutoff was used to determine significance (see Supplemental Methods).

gene MCO4_b (NVIE_019250), was the most upregulated gene ( $\log _{2}$ fold change (FC) of 6.99) and CBP_a (NVIE_001000), a gene encoding a putative surfaceassociated $\mathrm{Ca}^{2+}$ binding protein, was the most downregulated $\left(\log _{2} \mathrm{FC}-3.51\right)$.

\section{Genes encoding MCOs and associated proteins}

$\mathrm{Cu}$-limitation induced the expression of several proteins possibly involved in $\mathrm{Cu}$ uptake and transport. Previously, the two domain MCOs (2d MCOs) [32, 33] of $N$. viennensis were phylogenetically compared to other archaeal and bacterial 2d MCOs and were divided into four separate lineages (MCO1-4) [9]. MCOs belonging to lineage 1 (MCO1) were only found in thaumarchaeal genomes, whereas MCOs belonging to lineage 4 (MCO4) were only present in the order Nitrososphaerales and the genera Nitrosopumilus and Nitrosarchaeum [9]. MCOs of the type encoded by MCO1 and MCO4 genes contain three types of $\mathrm{Cu}$ centers (T1-T3), while MCO4 has an extra blue copper domain [9].

In this study, two highly upregulated MCO4 genes, MCO4_a (NVIE_017730; $\log _{2}$ FC 4.27) and MCO4_b (NVI_019250; $\log _{2}$ FC 6.99), and one moderately 


\section{A RPKM}

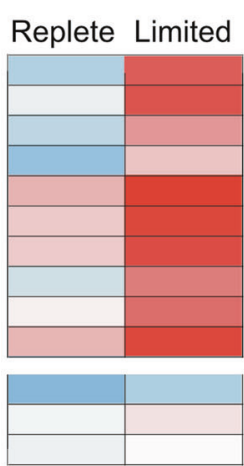

RPKM

Replete Limited

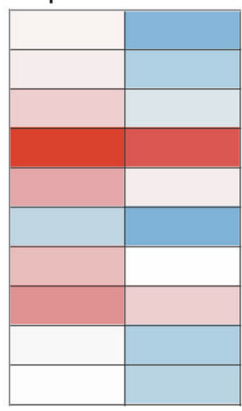

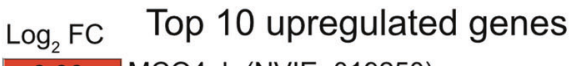

\begin{tabular}{|l|}
\hline 6.99 \\
\hline 5.53 \\
\hline 4.75 \\
\hline 4.49 \\
\hline 4.39 \\
\hline 4.27 \\
\hline 4.24 \\
\hline 4.23 \\
\hline 4.15 \\
\hline 4.11 \\
\hline
\end{tabular}

MCO4_b (NVIE_019250)

exported protein of unknown function (NVIE 001850)

protein of unknown function (NVIE_014210)

membrane protein of unknown function (NVIE_014220)

protein of unknown function (NVIE_018920)

MCO4 a (NVIE 017730)

protein of unknown function (NVIE_1990)

hypothetical protein (NVIE_1444)

protein of unknown function (NVIE 012190)

protein of unknown function with C-terminal blue type 1 copper domain (NVIE_012190)

1.39 PERM_a (NVIE_001900)

1.33 PERM_b (NVIE_000590) $\}$ additional upregulated genes

0.81 MCO1 (NVIE_000600)

\section{$\log _{2}$ FC Top 10 downregulated genes}

-3.51 CBP_a (NVIE_001000)

$-2.32$

$-2.02$

putative transposase IS605 OrfB family (NVIE_017190)

$-1.81$

conserved protein of unknown function (NVIE_021040)

$-1.73$

TRAM domain-containing protein (NVIE_003690)

$-1.67$

protein of unknown function (NVIE_028970)

$-1.65$

protein of unknown function (NVIE_010050)

putative cupredoxin (NVIE_002250)

-1.63 protein of unknown function (NVIE_019730)

-1.60 protein of unknown function (NVIE_006760)

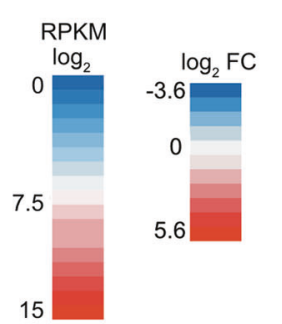

B

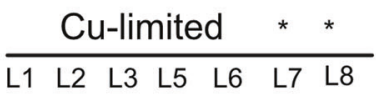
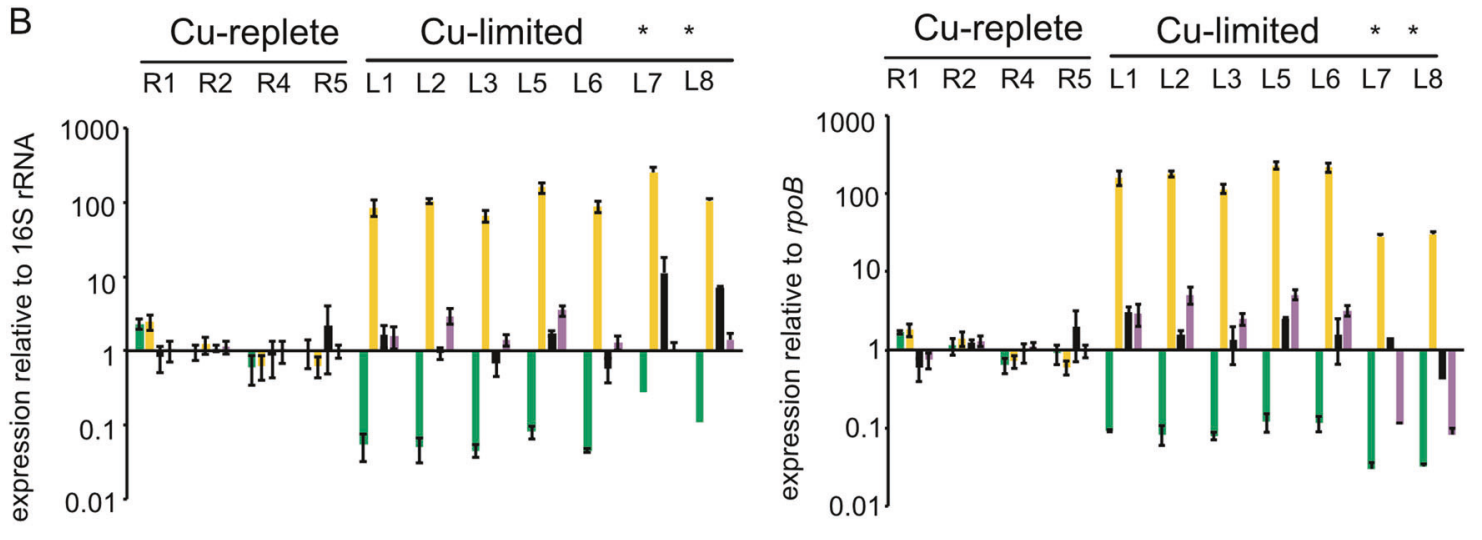

Genes

\footnotetext{
PERM_b (NVIE_000590)

MCO4_b (NVIE_019250)

MCO1 (NVIE_000600)

CBP_a (NVIE_001000)
}

* Duplicate cultures harvested on Day 13 and subjected to proteomic and RT-qPCR analyses.

Fig. 3 Top upregulated and downregulated genes. a Top 10 up and downregulated genes and additional upregulated genes. A $p$ value $<$ 0.01 cutoff was used to determine significance. b qPCR results of select up and downregulated genes relative to the $16 \mathrm{~S}$ rRNA and $r p o B$

upregulated MCO1 (NVIE_000600; $\log _{2}$ FC of 0.81) were identified. In addition, a putative zinc/iron permease gene adjacent to MCO1, PERM_b (NVIE_000590; $\log _{2}$ FC gene in biological replicates of $\mathrm{Cu}$ limited and $\mathrm{Cu}$ replete cultures. A logarithmic scale was used for the y-axis. Samples L7* and L8* are $\mathrm{Cu}$-limited cultures collected on Day 13 (see Fig. 1) and subjected to proteomic and RT-qPCR analysis.

1.33), and another zinc/iron permease, PERM_a (NVIE_001900; $\log _{2}$ FC 1.39), were also differentially expressed. Both MCO4s and the MCO1 were also detected 
in the proteome of the two tested $\mathrm{Cu}$-limited cultures (Dataset S1). The two zinc/iron permeases were absent from the proteome, likely attributed to the protein extraction method that was not specifically adapted for membrane proteins. In RT-qPCR, general trends of selected up and downregulated genes were also confirmed across all copper limited samples used for transcriptomics or proteomics: MCO4_b (NVIE_019250) was highly expressed, and PERM_b (NVIE_000590) and MCO1 (NVIE_000600) were moderately expressed, whereas CBP_a (NVIE_001000) was under-expressed relative to the housekeeping genes $16 \mathrm{~S}$ rRNA and $r p o B$ in $\mathrm{Cu}$-limited cultures (Fig. 3b; see Table S2 for primers).

Comparison of MCO1 and MCO4 with other $2 \mathrm{~d}$ MCOs from bacteria (Fig. S3) suggests that the $\mathrm{T} 1 \mathrm{Cu}$ site in these MCOs are coordinated by two histidines, a cysteine and either a methionine (in MCO4_a; NVIE_017730) or leucine (in MCO1; NVIE_000600 and MCO4_b; NVIE_019250). In bacteria, the T2/T3 $\mathrm{Cu}$ sites of MCOs can reduce oxygen to water and oxidize organic (e.g., siderophores, phenolic compounds) or inorganic (e.g., $\mathrm{Cu}^{+}, \mathrm{Fe}^{2+}$ ) electron acceptors [17, 32] via the $\mathrm{T} 1 \mathrm{Cu}$ site [34]. MCOs in archaea could use a similar mechanism to oxidize $\mathrm{Cu}^{+}$to $\mathrm{Cu}^{2+}$, for example to make $\mathrm{Cu}$ available to cells as discussed below.

Interestingly, genes for proteins requiring $\mathrm{Cu}$ (like MCOs) were upregulated while the organism was under $\mathrm{Cu}$ limitation. One possible explanation for this observation is that $\mathrm{Cu}$ limitation does not affect transcription of these MCO genes directly, but rather their stability and proper function following translation. This is true of MCOs with ferroxidase activity in $\mathrm{Cu}$-deficient mammals [35]. Similarly, in expression studies of MCOs in the yeast Candida albicans, some MCO transcripts were upregulated under $\mathrm{Cu}$ limitation while others were unaffected [36]. This implies the cell recognizes that the proteins are defective and increases transcription to make new proteins while attempting to remedy the situation. In this scenario, improperly folded proteins rather than direct $\mathrm{Cu}$-limitation would be inducing a transcriptional response.

Another possibility is that MCOs make $\mathrm{Cu}$ more bioavailable to cells. In Saccharomyces cerevisiae, the MCO Fet3p oxidizes iron which is then transported into the cell via a permease [37]. Perhaps a similar strategy is employed for $\mathrm{Cu}$ transport into AOA cells using MCOs and permeases, whose genes are directly linked in the genome (i.e., NVIE_000600 and NVIE_000590; NVIE_026950 and NVIE_026940). In addition, Escherichia coli has an MCO, $\mathrm{CueO}$, that has been shown to oxidize $\mathrm{Cu}^{+}$to $\mathrm{Cu}^{2+}$ [38]. MCOs in AOA could potentially oxidize $\mathrm{Cu}^{+}$to $\mathrm{Cu}^{2+}$ which in turn could be more readily transported by the ZIP permeases. However, the hypothesis that these MCOs and permeases are involved in $\mathrm{Cu}$ transport has to be experimentally validated.

\section{Genes encoding Cu-containing Cop proteins and their possible regulation}

A putative $\mathrm{Cu}$-storage protein, Csps (NVIE_028200), was identified and upregulated in $N$. viennensis under $\mathrm{Cu}$ limitation. This Csps contains 18 cysteine residues (15.3\% of the amino acid sequence) and is similar (28.44\% identity; BLASTP $2.10 .0+$ analysis $[39,40]$ ) to a $\mathrm{Cu}$-storage protein found in Methylosinus trichosporium OB3b, MtCsp1. A study of $M$. trichosporium $\mathrm{OB} 3 \mathrm{~b}$ showed that under $\mathrm{Cu}$ limitation MtCsp1 stores $\mathrm{Cu}^{+}$for use by its particulate methane monooxygenase, allowing cells to grow on methane when $\mathrm{Cu}$ is limiting [41]. Perhaps a similar strategy is used by $N$. viennensis to gather enough $\mathrm{Cu}$ for its AMO complex.

Cop proteins also seem to play a role in $\mathrm{Cu}$ limitation, as several of their genes were upregulated including: two cop $C / D$ genes, copC/D_a (NVIE_014300) and cop $C / D \_b$ (NVIE_014310). Both proteins are fusions of CopC and CopD domains, and their genes together with neighboring genes form part of a larger cluster comprising 25 genes of which 15 were upregulated (Fig. 4a). In bacteria, CopC is a hypothetical chaperone located in the periplasm that brings $\mathrm{Cu}$ to $\mathrm{CopD}$, an inner membrane protein, perhaps helping to transport $\mathrm{Cu}$ into the cytoplasm [21]. Alignment of the $N$. viennensis $\mathrm{CopC} / \mathrm{D}$ amino acid sequences to $\mathrm{CopC}$ representative sequences from the Lawton et al. 2016 study [21] showed they were most similar to CopC from M. trichosporium OB3b (Mst-CopC, Fig. S4). Mst-CopC has one binding site for $\mathrm{Cu}^{2+}$ (Fig. S4). CopCs similar to Mst-CopC, with one $\mathrm{Cu}^{2+}$ binding site, are the most common type of CopC proteins [21]. In these $\mathrm{CopC}$ proteins, a methionine rich region that would bind $\mathrm{Cu}^{+}$is missing [21]. The missing methionine residues have been noted to occur in species (including $N$. viennensis) that are missing copA and $\operatorname{cop} B$, encoding for a multicopper oxidase and outer membrane protein respectively, from the classical $\operatorname{cop} A B C D$ operon [42]. Furthermore, Gram-positive bacteria were observed to not only lack the methionine residues, but to also contain a fusion of CopC/D [42]. This fusion was suggested to be relevant for Gram-positive bacteria due to the absence of a periplasm (defined as a space between two membranes) when compared to Gram-negative bacteria [42]. Therefore, the lack of a true periplasm in Thaumarchaeota might also account for the CopC/D fusion protein that is conserved across the phylum (Fig. S5).

$\mathrm{CopC}$ and $\mathrm{CopD}$ are primarily involved in $\mathrm{Cu}$ resistance, but some exceptions are known. In Pseudomonas fluorescens SBW25, an organism also lacking CopA and CopB homologs, overexpression of $\operatorname{cop} C D$, resulted in hypersensitivity to $\mathrm{Cu}$ [24] supporting the idea that CopCD is involved in $\mathrm{Cu}$ uptake in some microorganisms. In two marine AOA species, the expression of $\mathrm{CopC} / \mathrm{D}$ was 

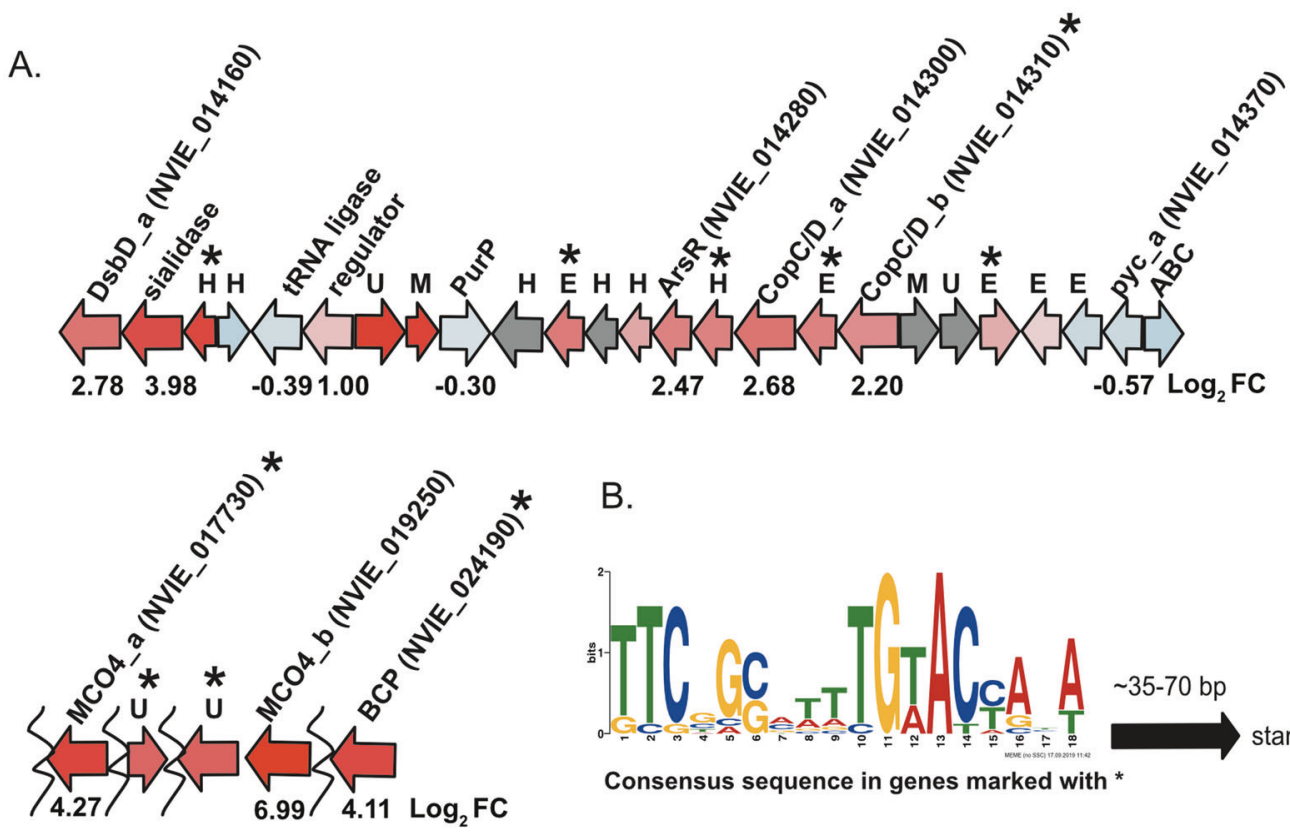

B.

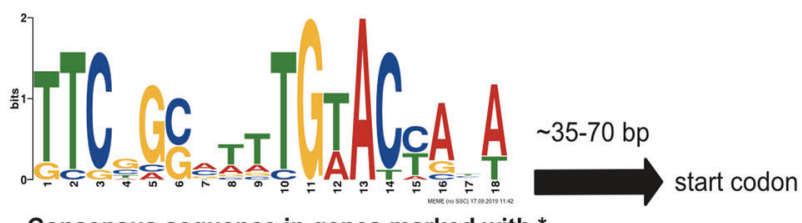

H hypothetical protein

E exported protein of

M membrane protein of

Uprotein of unknown unknown function unknown function function

C.
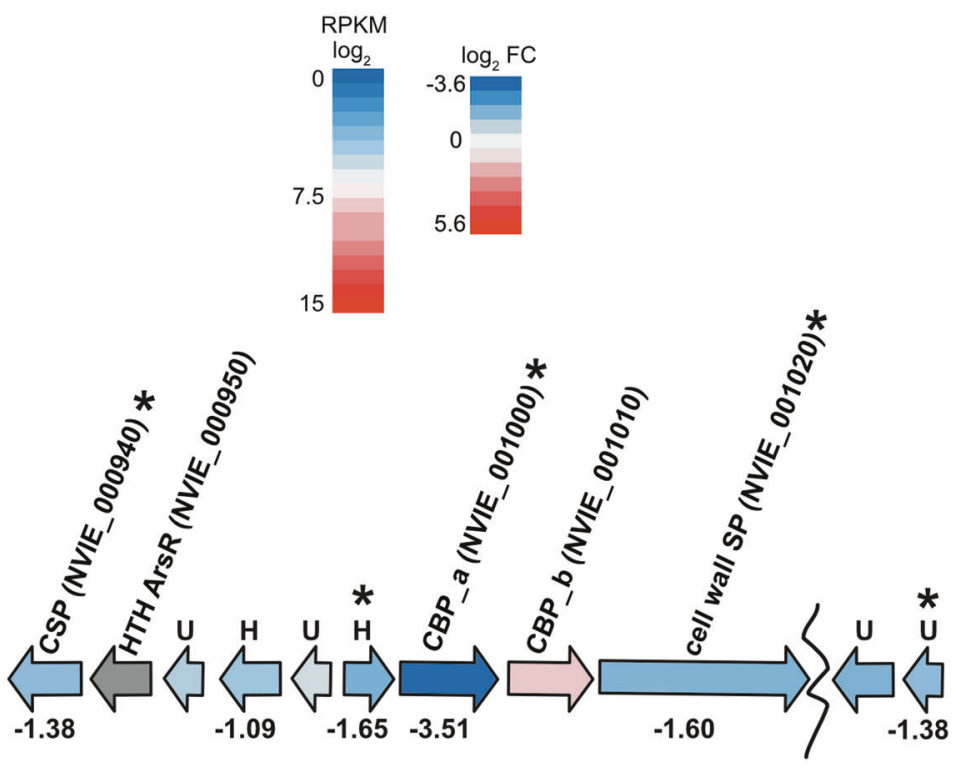

D.

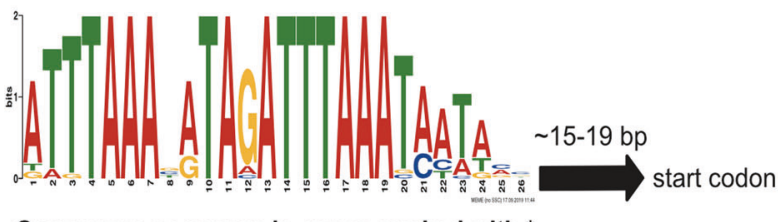

Consensus sequence in genes marked with *

increased as a response to oxidative stress, and was suggested to represent a strategy to reduce oxidative damage through copper accumulation [43].
The expression of CopCD under $\mathrm{Cu}$ limitation was also proposed to be regulated by CopRS [24], a two-component regulatory system that is known to control $\operatorname{cop} A B C D$ 
Fig. 4 Upregulated and downregulated gene clusters. a Upregulated gene clusters along with their gene expression information. Curved line indicates genes are in another gene cluster relative to the other genes. Gene arrow colors represent $\log _{2}$ fold change of genes in copper limited cultures. Gray arrows are not differentially expressed. b A motif consensus sequence found in certain upregulated genes marked with an asterix $(*)$ in $\mathbf{a}$. DsbD, disulfide bond oxidoreductase D family protein; sialidase, putative sialidase neuraminidase family protein; tRNA ligase, putative threonyl/alanyl tRNA ligase; regulator, putative transcriptional regulator; PurP, 4-carboxamide-1-(beta)-Dribofuranosyl 5'monophosphate ligase; ArsR, transcriptional regulator ArsR; pycA, putative plastocyanin $\mathrm{Cu}$ containing protein/azurin family; $\mathrm{ABC}$, putative $\mathrm{ABC}$ transporter; $\mathrm{MCO}$, multicopper oxidase; $\mathrm{BCP}$, protein of unknown function with $\mathrm{C}$-terminal blue type(1) copper domain. Locus tag information for all genes in this figure can be found in Dataset S1. c Gene clusters of top downregulated genes that were found to harbor a motif sequence along with their gene expression information. Curved line indicates genes are in another gene cluster relative to the other genes. Gene arrow colors represent $\log _{2}$ fold change of genes in copper limited cultures. Gray arrows are not differentially expressed. d A motif consensus sequence found in certain upregulated genes marked with an asterix in c. PUA, PUA domain containing protein; Lrp, transcriptional regulator Lrp family; psmB1, psmB1 proteosome subunit beta; CSP, cell surface protein w/ DUF 11 domain; HTH-ArsR, hypothetical protein w/HTH ArsR; CBP, cell surface-associated $\mathrm{Ca}^{2+}$ binding domain protein aemolysin type; cell wall SP, putative cell wall surface anchor family protein. Gene locus information for all genes in figure can be found in Dataset S1.

operons [44]. Indeed, an upregulated potential twocomponent system under $\mathrm{Cu}$ limitation was found in $N$. viennensis (NVIE_030040, $\log _{2}$ FC 1.77; NVIE_030060, $\log _{2}$ FC 1.51) with NVIE_030040 sharing a $27.97 \%$ identity to CopR from P. fluorescens SBW25 (PFLU_1576 or cusR, NCBI accession number CAY47824.1) [39, 40]. Potentially, these two proteins could act as CopR and CopS respectively. If so, a regulatory system induced by $\mathrm{Cu}$ limitation, similar to that proposed in P. fluorescens SBW5, is likely.

Alternatively, it was suggested that in the bacterium Corynebacterium glutamicum CopC could participate in the assembly of cytochrome $a a_{3}$ oxidase (complex IV) as an intermediate $\mathrm{Cu}$ chaperone before $\mathrm{Cu}$ is incorporated into the cytochrome oxidase [45]. This could also be true for $N$. viennensis as the cytochrome oxidase in Thaumarchaeota is classified as type $a a_{3}[46,47]$. Whether or not $\mathrm{Cu}$ needs to be transported into the cell before incorporation (as for $c b b_{3}$ oxidase in the bacterium Rhodobacter capsulatus [48, 49]) or whether this takes place in the (pseudo-)periplasm (as in the model for cytochrome $a a_{3}$ oxidase in Paracoccus denitrificans [50]) is unclear.

Genomic organization in N. viennensis revealed that the Cop genes are spread out in the genome with CopC/D genes residing in one genomic region, CopA1 (NVIE_008380) in another, and CopA2 (NVIE_012900), CopZ (NVIE_012910), and one of three CopT genes (NVIE_012920) residing in a third genomic region (Fig. S6). In $N$. viennensis, CopA1 and CopA2 are P1B-type (also known as CTPx-type) ATPase proteins (Fig. S7a, b respectively) and not the CopA-MCO discussed above. This discrepancy is a result of redundant naming in the literature. In $N$. viennensis, CopA1 and CopA2 refer exclusively to P1B-type ATPase proteins. A number of studies have shown that P1-type ATPases can function as exporters and importers of ions [20]. CopZ and CopT are located in the same gene cluster as CopA2 (Fig. S6). CopZ could deliver $\mathrm{Cu}^{+}$to CopA1 or CopA2 [51] for export. CopT is similar (38\% identity) to a novel archaeal transcriptional regulator (SO2652) that is hypothesized to control the expression of Cop genes in Sulfolobus solfataricus P2 [19]. Of these Cop genes in $N$. viennensis, only the CopC/D genes and the CopA2 gene were differentially upregulated under $\mathrm{Cu}$ limitation (Dataset S1). This is unusual for CopA2 as it is assumed to be an exporter, but perhaps it is constitutively expressed to respond to sudden fluctuations in $\mathrm{Cu}$ availability. How these Cop genes are transcriptionally regulated remains an open question.

\section{Shared promoter motifs in differentially upregulated genes}

To investigate possible regulatory mechanisms of the upregulated genes, upstream regions from translational start sites were analyzed for shared motifs. Initially, no motifs were identified in the upstream regions of the top 25 upregulated genes. The analysis was repeated focusing on 15 upregulated genes known or suspected to be involved in $\mathrm{Cu}$ metabolism. These included the upregulated genes with a $\log _{2} \mathrm{FC}>1.5$ found in close proximity to the two CopC/D genes (NVIE_014300 and NVIE_014310) in the genome, upregulated genes next to the highly upregulated MCO4_b (NVIE_019250), and genes specifically associated with $\mathrm{Cu}$ from the top 25 upregulated genes (see Dataset S1 for a full list of genes).

A motif with a consensus sequence of 5'TTCSGSMTTTGWACYANT-3' was found 12 times starting at position -35 to -70 with respect to the potential translational start codon of the respective gene (Fig. 4b). In particular, it was found twice in front of one of the CopC/D genes, copC/D_b (NVIE_014310) (Fig. S8a). For some of the analyzed genes, the motif was found in the upstream region on the opposite strand in reference to the gene orientation (Fig. S8a). This was the case for an upregulated exported protein of unknown function near the CopC/D genes (NVIE_014340), a protein of unknown function (NVIE_019240) that directly follows the highly upregulated MCO4_b (NVIE_019250), a highly upregulated gene of unknown function near the $\operatorname{cop} C / D$ region of the genome (NVIE_1444), and MCO4_a (NVIE_017730). Regarding NVIE_1444, the motif was also repeated. A motif recruiting a transcriptional activator on the opposite strand in 
reference to the transcribed gene was previously observed upstream of the malZ gene in E. coli. [52]. Once found, the specific motif sequence was screened against the top 25 upregulated genes. This resulted in the additional discovery of the motif in the second most upregulated gene (NVIE_001850, $\log _{2}$ FC 5.53), an exported protein of unknown function. The presence of this motif in various upregulated genes could indicate that it is involved in transcription under $\mathrm{Cu}$ limitation.

Most of the upregulated genes with the motif, or in a putative operon with the motif, encode hypothetical or unknown proteins. An ArsR family transcriptional regulator (NVIE_014280), a family known to be involved in metal stress [53], was one of the upregulated genes near the CopC/D cluster and is presumably co-transcribed with NVIE_014290 containing the identified motif (Fig. 4a). Another gene, NVIE_014160 (DsbD_a), a disulfide bond oxidoreductase D (DsbD) family protein, was located in a putative operon starting with NVIE_1444. DsbD family proteins shuttle electrons from the cytoplasm to the periplasm to reduce oxidized disulfide bonds and/or to adjust the redox status of prokaryotic cells. Since further counterparts of the redox system are missing, the upregulation of $d s b D$ could be a cellular response to rectify damage to disulfide bonds induced by a lack of $\mathrm{Cu}$ rather than a mechanism to adjust the cell's redox state. Alternatively, DsbD, like its homolog $\mathrm{ScsB}$, could bind $\mathrm{Cu}^{+}$before passing it to a $\mathrm{Cu}$ chaperone in the periplasm [54, 55], thus sequestering $\mathrm{Cu}$ rather than removing it (as in $S$. enterica [56]).

\section{Downregulated genes}

A common motif was also searched for in the upstream region of the top 25 downregulated genes. A motif with a sequence of 5'-RATTTAAABATAGATTTAAATAATA AS-3' was identified in five of the top 25 downregulated genes (Fig. 4c, d and S8b): NVIE_001000 (the most downregulated gene), NVIE_0009400, NVIE_0009900, NVIE_001020, and NVIE_019740. NVIE_019740 appears to form an operon with NVIE_019730, which is also in the top 25 downregulated genes. Therefore, only the upstream sequence of NVIE_019740 was used for the motif search. NVIE_001000 and NVIE_001020 are suggested to code for proteins involved with the cell surface while the rest are annotated as hypothetical proteins or proteins of unknown function.

The motif was also present in similar genes from Candidatus Nitrososphaera evergladensis and Candidatus Nitrososphaera gargensis, the two most closely related Thaumarchaeal species to $N$. viennensis (see Dataset $\mathrm{S} 1$ for a list of the identified genes and Fig. S6 for alignments of the motif across all three species). The conservation of this promoter in these other species suggests that a similar transcriptional pattern would be observed in both $\mathrm{Ca}$. N. evergladensis and $\mathrm{Ca}$. N. gargensis under $\mathrm{Cu}$ limitation.

The most strongly downregulated gene in $\mathrm{Cu}$-limited cultures was a putative surface-associated $\mathrm{Ca}^{2+}$-binding protein (CBP_a, NVIE_001000; $\log _{2}$ FC -3.51) (Fig. 3a). Perhaps the cell remodels its surface to accumulate $\mathrm{Cu}$ in response to $\mathrm{Cu}$ limitation as previously reported [11, 57]. It is also possible that the $\mathrm{Cu}$-limited cells inhibit cell aggregation by downregulating the putative surface-associated $\mathrm{Ca}^{2+}$ binding protein to enhance $\mathrm{Cu}$ uptake.

\section{Responses in energy metabolism and carbon fixation}

In accordance with growth inhibition upon $\mathrm{Cu}$ limitation, most genes central for energy metabolism, i.e., the AMO complex, electron transport chain (ETC), and genes involved in carbon fixation, were downregulated. For the ETC, these included all subunits of complex I, most of the genes encoding for the archaeal ATP synthase (complex V), and genes potentially encoding plastocyanins [8]. It is hypothesized that plastocyanins form part of the archaeal HURM (hydroxylamine: ubiquinone redox module) and may shuttle electrons between protein complexes, similar to c-type cytochromes [58, 59]. Because of its ammoniaoxidizing metabolism, $N$. viennensis does not rely on complex I as a source of electrons for the ETC. Therefore, it has been suggested that complex I could be operating in reverse, possibly supplying a source of reducing equivalents to the cell for carbon fixation and biomass accumulation [58, 60, 61]. In this hypothesized model, complex I would consume $\mathrm{H}^{+}$generated by the ETC and deplete the available proton motive force (pmf) (Fig. 5).

In contrast to complex I and complex $\mathrm{V}$, other ETC components that contribute to pmf, (i.e., complex III (cytochrome b/b6 and Rieske [2Fe-2S]) and complex IV $(\operatorname{coxA} 1$ and $\operatorname{cox} B)$ ) were upregulated under $\mathrm{Cu}$ limitation (Fig. 5). A possible explanation for the ETC complexes being regulated in different ways is that the cell is attempting to conserve pmf, given that the pmf consuming complexes (complex I and complex V) were downregulated while the pmf contributing complexes (complex III and complex IV) were upregulated. A second possibility is that complex III and complex IV are upregulated to maintain the quinone and plastocyanin electron carriers in an oxidized state. The shift towards oxidized electron carriers could help to ensure that any electrons introduced into the ETC by the AMO complex are channeled directly towards the ETC because of the high supply of available electron acceptors.

Ammonia monooxygenase genes amoA, amoB, amoX, and amoCl were downregulated while AMO subunits 


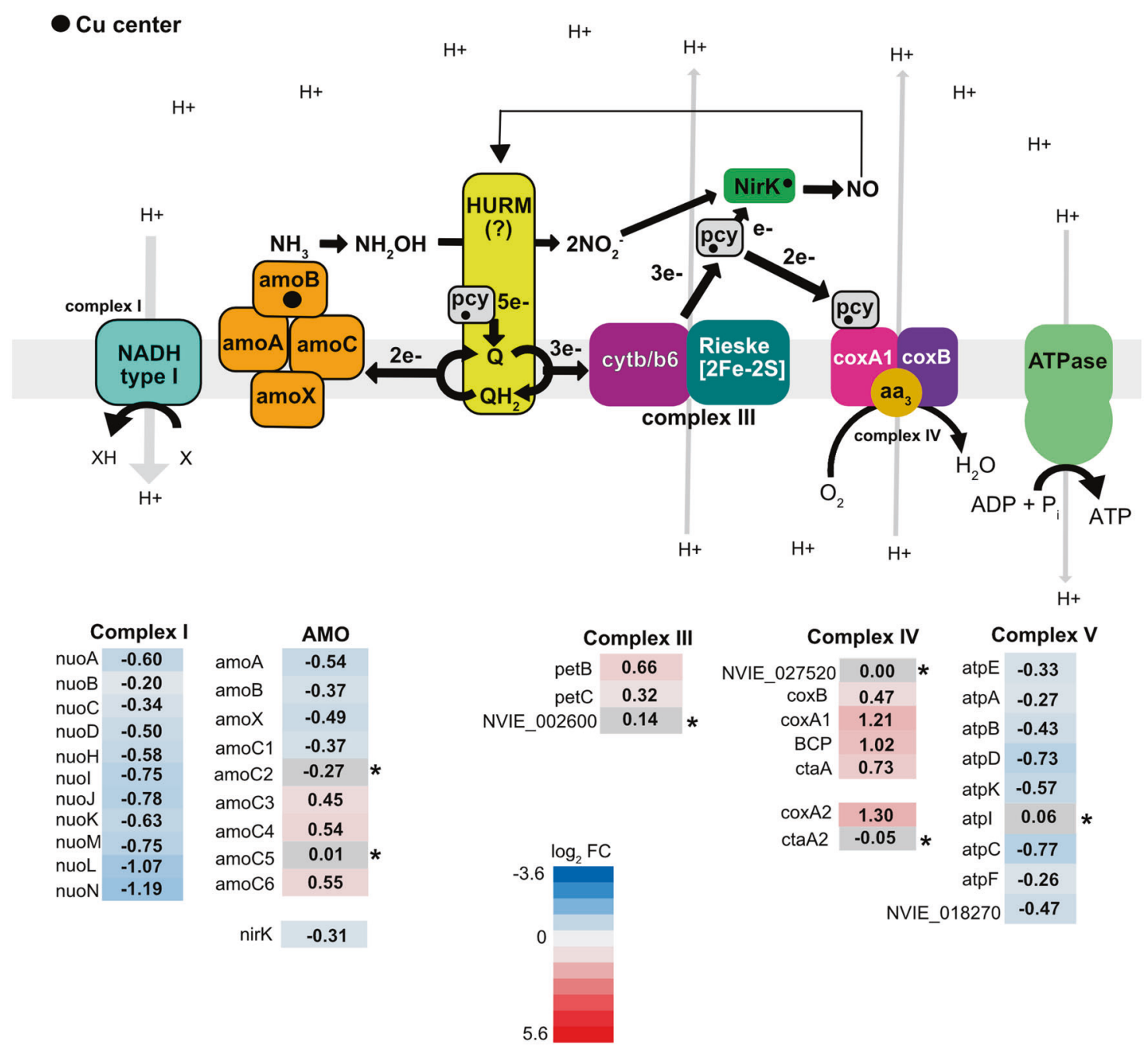

Fig. 5 A schematic showing the expression of $\mathrm{Cu}$ and non-Cu containing genes potentially involved in the ammonia oxidation and electron transport pathways. Blue color is downregulated and red is upregulated; circle stands for $\mathrm{Cu}$ with an unknown redox state. A grey background with an asterix represents genes that were not differentially expressed. A $p$ value $<0.01$ cutoff was used to determine significance. (pcy) NVIE_002600 and NVIE_027550 (putative blue (type 1) copper domain containing proteins), NVIE_027520 cytochrome c oxidase subunit, NVIE_018270 putative ATPase subunit H, HURM; represents the hydroxylamine ubiquinone redox module [58] yet to be identified in AOA. NVIE gene information for all genes in this figure can be found in Dataset S1. Figure adapted from Qin et al. [26], Kerou et al. [9], and Kozlowski et al. [59].
amoC3, amoC4, and amoC6 [9] were upregulated (Fig. 5). There are six copies of amoC in the genome [9] and it is unknown if all or only some interact with the AMO complex in N. viennensis. However, it was suggested that additional copies of amoC could ensure that the AMO enzyme is stable under conditions of stress [9] similar to findings in AOB [26, 62]. Although the cell seems to be reacting to energy limitation, AMO, the only source of energy, is downregulated. This is counterintuitive but can be explained by limited $\mathrm{Cu}$ available to the cell, which is needed for this enzyme complex. Consequently, a transcriptional response that lowers the transcription of AMO is initiated. It should be noted that although transcription of AMO genes is lower under $\mathrm{Cu}$ - limited conditions compared to $\mathrm{Cu}$-replete conditions, they still have some of the highest overall transcription levels in the cell (Dataset S1).

Genes involved in nitrogen uptake also showed distinct expression patterns. $N$. viennensis encodes three ammonia transporters, two urea transporters, and a urease operon (Fig. 6). Two of the ammonia transporters are thought to be high-affinity transporters and the other to be a low-affinity transporter [63]. The low-affinity transporter, amt3 (NVIE_023840) (Fig. 6) was downregulated under $\mathrm{Cu}$ limitation while the presumed high-affinity transporters were unaffected. The differential regulation of ammonia transporters in response to environmental stimuli was also observed in N. maritimus [64]. Genes within the urease 
Fig. 6 A schematic showing the expression of ammonia transporter, urease, and transcriptional regulator genes. For RPKM $\log _{2}$ and $\log _{2}$ $\mathrm{FC}$, blue color is downregulated and red is upregulated. A grey background with an asterix represents genes that were not differentially expressed. A $p$ value $<0.01$ cutoff was considered as significantly expressed.

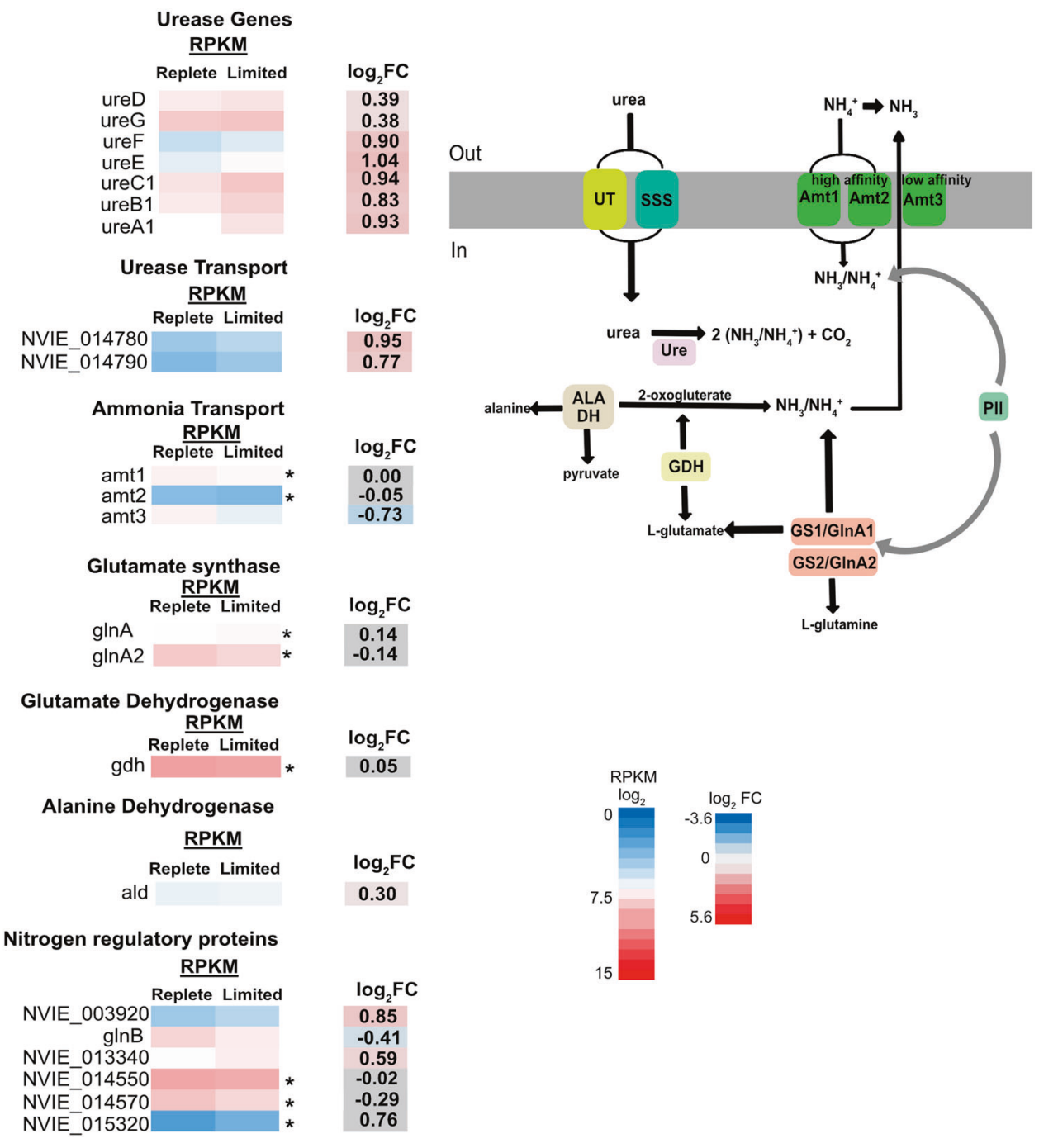

operon and urea transporters were all upregulated. The downregulation of the low-affinity transporter and the upregulation of the urease genes and urea transporters (even in the absence of urea) initially suggest a cellular response to ammonia limitation. This response regarding the lowaffinity ammonia transporter was shown in previous studies of $N$. viennensis and other AOA when the cells were starved of ammonia [26, 63, 64]. However, in this study, the cells appear to be starved of energy, not ammonia. This is shown by the clear presence of ammonium in the medium at the time the cultures were harvested (Fig. 1). Therefore, it is likely that these cellular responses are regulated by an arrest of the ETC, rather than the physical presence or absence of ammonia.

As previously mentioned, the expression of the presumed high-affinity ammonia transporters was unaffected. If these importers responded to energy limitation, they would likely be upregulated similar to the urea transporters. This not being the case, it implies that their expression is regulated by a different system that could potentially sense the physical presence or absence of ammonia despite the energy-limited state of the cell. Moreover, the lack of differential expression in ammonia assimilation enzymes indicates that these proteins are unaffected by the low energy state of the cell and/or support the assumption that ammonia assimilation is not a limiting growth factor for the cell. A complex regulatory system involving nitrogen and energy should not be surprising as these two substrates are fundamentally intertwined in ammonia-oxidizing microorganisms.

$\mathrm{Cu}$-limitation resulted in downregulation of genes encoding enzymes that consume NADPH (e.g., asd, $m s r$ ) in the 3-hydroxypropionate/4-hydroxybutyrate (3HB/4HB) carbon fixation cycle (Fig. S9). Due to the low energy status of the cell, NADPH reducing equivalents, normally available to reduce inorganic carbon into organic carbon compounds, is likely scarce. As discussed above, one source of reducing equivalents could be the reverse complex I 
reaction (Fig. 5). However, reverse complex I would be unable to directly produce $\mathrm{NAD}(\mathrm{P}) \mathrm{H}$ due to the lack of $n u o E$, nuоF, and nuoG subunits in $N$. viennensis [9] and other archaea [65].

The non-oxidative pentose phosphate pathway (which produces precursors that can be converted to nucleotides [66]), ribosomal proteins, information processing genes, and most of the lipid biosynthesis pathway were also downregulated (Dataset S1). These observations match the functional enrichment of translation, replication, and nucleotide metabolism genes within the downregulated group (Fig. 2) and the general growth impairment of cells upon $\mathrm{Cu}$ limitation (Fig. 1).

\section{Different reactions to $\mathrm{Cu}$ limitation in N. viennensis and N. maritimus}

While $N$. maritimus showed similar overall responses to $\mathrm{Cu}$ limitation by downregulating general energy and carbon fixation pathways and slowing growth, $\mathrm{Cu}$-acquisition or coping with $\mathrm{Cu}$-limitation clearly differs from that in $N$. viennensis [26] (Fig. 7). Opposite reactions of complex III and complex IV in the ETC in response to the same environmental stimuli indicate a distinct regulation of energetic pathways between $N$. viennensis and $N$. maritimus, although the pathway itself is highly conserved among AOA. This distinction in regulatory patterns is also seen by the differing response in expression of homologous MCO4 [9] genes between the two organisms. Curiously, homologous MCO1 genes [9] show conflicting patterns in N. maritimus. In the case of $\mathrm{MCO} 4$, this would suggest that $\mathrm{MCO} 4$ plays a different physiological role in $N$. maritimus, possibly one that is not $\mathrm{Cu}$ related. In addition, each organism contains at least one CopC/D fusion protein and a lone CopD protein. Based on this comparison, $N$. viennensis relies on upregulation of the CopC/D fusion protein while $N$. maritimus rather upregulates copD. As CopD is a membrane bound transporter, N. maritimus likely utilizes a chaperone protein other than CopC to deliver $\mathrm{Cu}$ to $\mathrm{CopD}$ for transport into the cell. Alternatively, CopC/D could be linked to the proper assembly and function of complex IV as both are upregulated in N. viennensis and both are downregulated in $N$. maritimus. A final key difference is the upregulation of $\mathrm{DsbD}$ family proteins (arCOG02398) in N. viennensis. Perhaps, the upregulation of $\mathrm{MCO} 4$ and $\mathrm{DsbD}$ in $N$. viennensis, which are presumed to interact with $\mathrm{Cu}^{+}$, and the downregulation or lack of response respectively in $N$. maritimus is a reflection of the different availability of $\mathrm{Cu}^{+}$in the very different environmental niches that these organisms occupy. Although $\mathrm{Cu}^{2+}$ is known as the bioavailable form in aerobic soil [67] and oxygenated seawater environments [68], $\mathrm{Cu}^{+}$is more likely to be found in soil environments that occasionally experience anoxic conditions and can possibly be stabilized at least to a certain

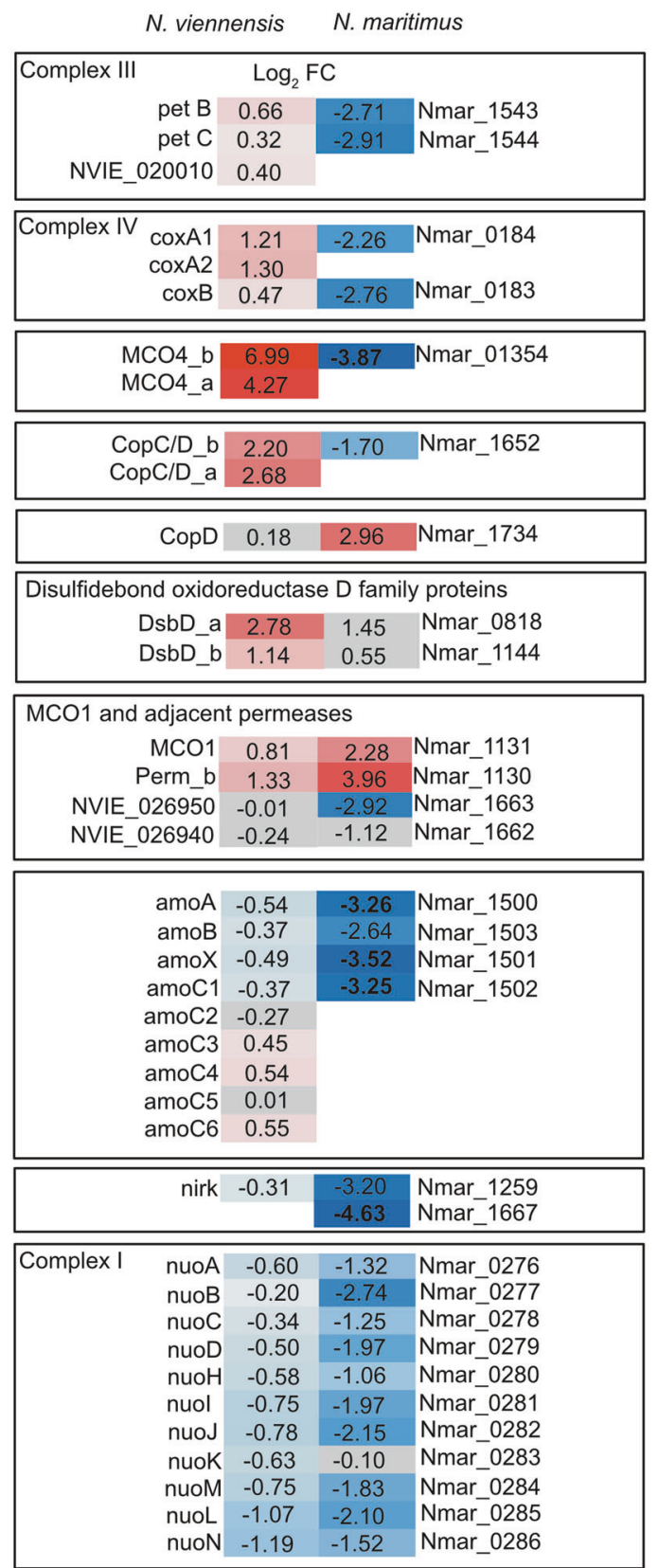

Fig. 7 Comparison of selected genes from $N$. viennensis and $N$. maritimus under $\mathrm{Cu}$ limitation. Values represent the $\log _{2}$ fold change of genes compared to $\mathrm{Cu}$-replete conditions $\mathrm{A}$ grey background represents genes that were not differentially expressed in $N$. viennensis ( $p$ value $<0.01$ ) or $N$. maritimus ( $p$ value $<0.05$ ) [26] respectively.

extent by humic acids upon soil re-oxidation $[69,70]$. Such environments include wetlands and riparian floodplain soils.

In neutral and alkaline soils, where organic and inorganic soil particles bind $\mathrm{Cu}^{2+}$ in soil solution and lower its bioavailability [71-73], these conditions could trigger the expression of CopC/D genes in soil organisms like $N$. viennensis. Another soil environment in which $\mathrm{Cu}$ concentrations are low and where expression of $\mathrm{Cu}$-uptake 
genes could be triggered are heavily weathered and eroded soils. A study by Jenkins et al. [74] observed low amoA gene abundances of AOA in such soils with lowered total $\mathrm{Cu}$ concentrations.

$\mathrm{Cu}-\mathrm{C}$ ratios and the types of ligands found in the soil environment differ from those in the marine environment [69]. In marine surface waters $10 \%$ of dissolved $\mathrm{Cu}$ has been shown to be $\mathrm{Cu}^{+}$and in estuarine environments up to $80 \%$ of $\mathrm{Cu}$ could be $\mathrm{Cu}^{+}[75,76]$. Copper in these environments can be bound by thiol ligands, reduced sulfur species or colloidal ligands that lower its bioavailability [77-79]. In surface waters of Hood Canal, Washington, bioavailable $\mathrm{Cu}^{2+}$ and AOA amoA gene abundances were found to be low in surface waters [78]. Thus, N. maritimus inhabiting these environments might trigger the expression of genes encoding transporters that differ from those observed in this study to facilitate uptake of ligand-bound $\mathrm{Cu}$.

\section{Conclusions}

Results show that $\mathrm{Cu}$-limitation in $N$. viennensis leads to high expression of several genes encoding MCOs and CopC/D proteins, which may be involved in $\mathrm{Cu}$ uptake. This study also puts forward the idea that $\mathrm{Cu}$ limitation triggers an energy conservation response in $N$. viennensis. This energy conservation response appears to downregulate the expression of genes involved in the consumption of the pmf, ammonia oxidation, and carbon fixation pathways while upregulating genes involved in ammonia acquisition by inducing the urease operon.

In summary, $\mathrm{Cu}$ uptake could involve binding and uptake of $\mathrm{Cu}^{2+}$ by CopC/D fusion proteins (Fig. 8). CopC could also act as a chaperone helping to assemble cytochrome $a a_{3}$ oxidase and AMO by transferring $\mathrm{Cu}^{+}$to these proteins. MCO1 and MCO4 could bind and oxidize $\mathrm{Cu}^{+}$to $\mathrm{Cu}^{2+}$, which could then be taken up either through a

\section{Cu center}
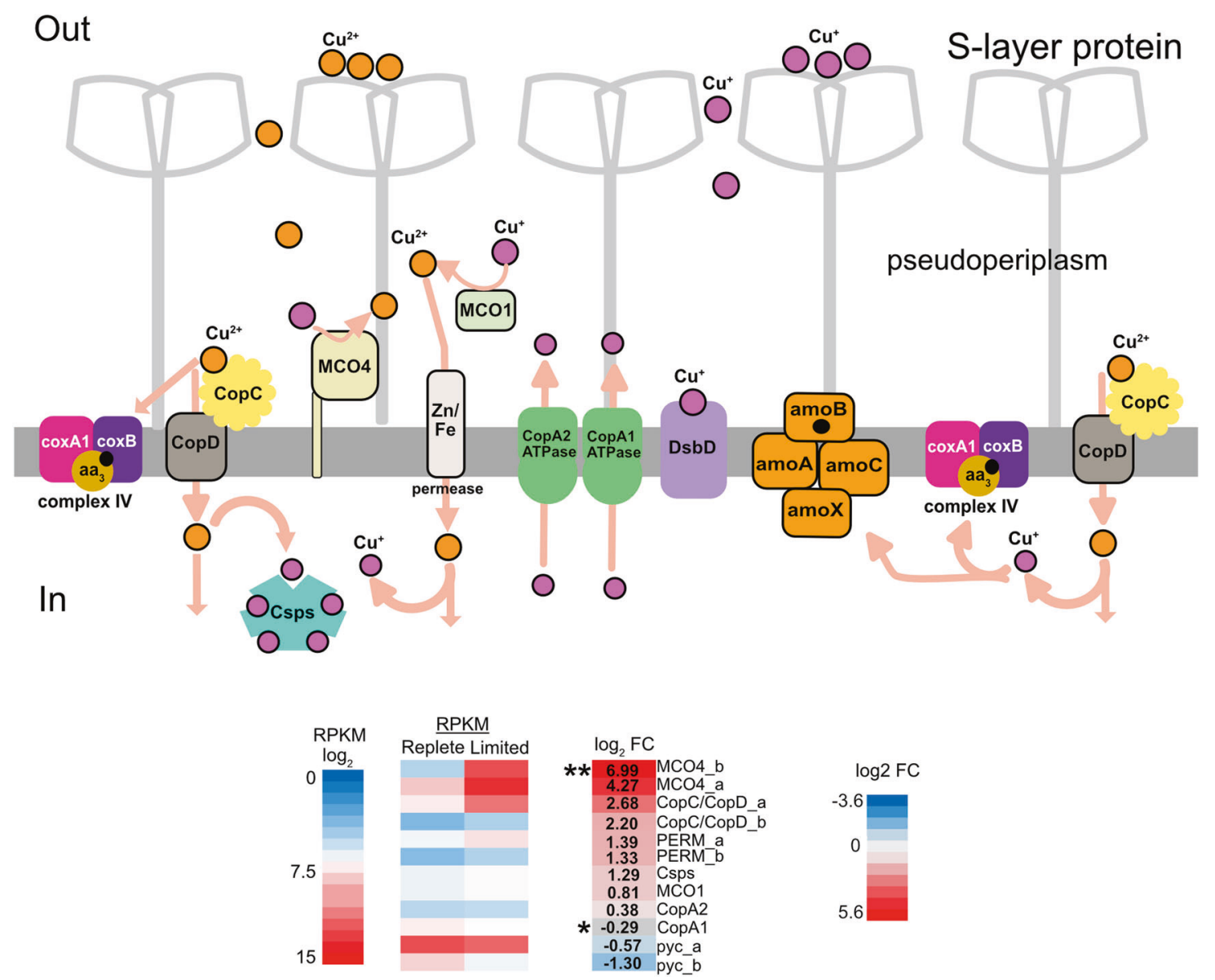

Fig. 8 A schematic showing the expression of MCOs and Cop genes under $\mathrm{Cu}$ limiting conditions. -1 circle stands for $\mathrm{Cu}$ with an unknown redox state, $\mathrm{Cu}^{2+}$, and $\odot \mathrm{Cu}^{+}$. For RPKM $\log _{2}$ and $\log _{2} \mathrm{FC}$, blue color is downregulated and red is upregulated. (**) $\log _{2}$ fold change value is higher than pictured in the scale. A grey background with an asterix represents genes that were not differentially expressed. A $p$ value $<0.01$ was considered as significantly expressed. 
permease (encoded adjacent to MCO1) or an unknown divalent transporter. Once acquired, Csps could sequester $\mathrm{Cu}$ inside the cell. CopA1/A2 could function as $\mathrm{Cu}$ exporters and DsbD could possibly bind $\mathrm{Cu}^{+}$and transfer it to chaperones in the periplasm for assembling $\mathrm{Cu}$ containing proteins or to import $\mathrm{Cu}$ into the cell.

Overall, this analysis proposes possible regulatory networks in terrestrial AOA, while highlighting distinct differences in adaptation strategies employed by different AOA clades in accordance to their ecophysiology.

Acknowledgements The authors would like to thank Herwig Lenitz, Sonja Tischler and Romana Bittner for technical support, Lokeshwaran Manoharan for bioinformatics input, Isabelle Anna Zink and Gabriella Paredes for their advice regarding qPCR methods, Thomas Rattei and Florian Goldenberg for providing access to the CUBE servers (U. Vienna), Sung-Keun Rhee (Chungbuk National University) for discussions and input on the copper model, and Amy Schmid (Duke University) for suggestions regarding analysis of the data. This study was supported by the Marie Skłodowska Curie Individual Fellowship (IF) CORA Project (grant no. 700788) (C.R.), by the Austrian Science Fund (FWF) DK+ project "Microbial Nitrogen Cycling: From single cells to ecosystems" (W1257) (L.H., B. B. and CR), MK was supported through the European Research Council Advanced Grant ERC-ADG 695192 and BB by the Uni:docs fellowship of the University of Vienna.

\section{Compliance with ethical standards}

Conflict of interest The authors declare that they have no conflict of interest.

Publisher's note Springer Nature remains neutral with regard to jurisdictional claims in published maps and institutional affiliations.

Open Access This article is licensed under a Creative Commons Attribution 4.0 International License, which permits use, sharing, adaptation, distribution and reproduction in any medium or format, as long as you give appropriate credit to the original author(s) and the source, provide a link to the Creative Commons license, and indicate if changes were made. The images or other third party material in this article are included in the article's Creative Commons license, unless indicated otherwise in a credit line to the material. If material is not included in the article's Creative Commons license and your intended use is not permitted by statutory regulation or exceeds the permitted use, you will need to obtain permission directly from the copyright holder. To view a copy of this license, visit http://creativecommons. org/licenses/by/4.0/.

\section{References}

1. Kuypers MMM, Marchant HK, Kartal B. The microbial nitrogencycling network. Nat Rev Microbiol. 2018;16:263-76.

2. Daims H, Lebedeva EV, Pjevac P, Han P, Herbold C, Albertsen $\mathrm{M}$, et al. Complete nitrification by Nitrospira bacteria. Nature. 2015;528:504-9.

3. van Kessel MAHJ, Speth DR, Albertsen M, Nielsen PH, Op den Camp HJM, Kartal B, et al. Complete nitrification by a single microorganism. Nature. 2015;528:555-9.

4. Schleper C, Nicol GW. Ammonia-oxidising archaea-physiology, ecology and evolution. In: Poole RK, editor. Advances in microbial physiology. Academic Press; Amsterdam. 2010. p. $1-41$.

5. French E, Kozlowski JA, Mukherjee M, Bullerjahn G, Bollmann A. Ecophysiological characterization of ammonia-oxidizing archaea and bacteria from freshwater. Appl Environ Microbiol. 2012;78:5773-80.

6. Kerou M, Schleper C. Nitrososphaera. In: Whitman, WB, Rainey, F, Kämpfer, P, Trujillo, M, Chun, J, DeVos, P, Hedlund, B, Dedysh S, editors. Bergey's manual of systematics of archaea and bacteria. John Wiley \& Sons, Inc. \& Bergey's Manual Trust; 2016.

7. Alves RJE, Minh BQ, Urich T, Von Haeseler A, Schleper C. Unifying the global phylogeny and environmental distribution of ammonia-oxidising archaea based on amoA genes. Nat Commun. 2018;9:1517.

8. Walker CB, de la Torre JR, Klotz MG, Urakawa H, Pinel N, Arp DJ, et al. Nitrosopumilus maritimus genome reveals unique mechanisms for nitrification and autotrophy in globally distributed marine crenarchaea. Proc Natl Acad Sci USA. 2010;107:8818-23.

9. Kerou M, Offre P, Valledor L, Abby SS, Melcher M, Nagler M, et al. Proteomics and comparative genomics of Nitrososphaera viennensis reveal the core genome and adaptations of archaeal ammonia oxidizers. Proc Natl Acad Sci. 2016;113:E7937-E7946.

10. Arp DJ, Chain PSG, Klotz MG. The impact of genome analyses on our understanding of ammonia-oxidizing bacteria. Annu Rev Microbiol. 2007;61:503-28.

11. Gorman-Lewis D, Martens-Habbena W, Stahl DA. Cu(II) adsorption onto ammonia-oxidizing bacteria and archaea. Geochim Cosmochim Acta. 2019;255:127-43.

12. Lide DR. CRC handbook of chemistry and physics: a ready reference book of chemical and physical data, 84th ed. CRC Press Taylor and Francis Group. Boca Raton. 2003.

13. Reyes C, Hodgskiss LH, Baars O, Kerou M, Bayer B, Schleper C, et al. Copper limiting threshold in the terrestrial ammonia oxidizing archaeon Nitrososphaera viennensis. Res Microbiol. 2020;171:134-42.

14. Gwak JH, Jung MY, Hong H, Kim JG, Quan ZX, Reinfelder JR, et al. Archaeal nitrification is constrained by copper complexation with organic matter in municipal wastewater treatment plants. ISME J. 2019;14:335-46.

15. Tourna M, Stieglmeier M, Spang A, Könneke M, Schintlmeister $\mathrm{A}$, Urich $\mathrm{T}$, et al. Nitrososphaera viennensis, an ammonia oxidizing archaeon from soil. Proc Natl Acad Sci USA. 2011;108:8420-5.

16. Stieglmeier M, Klingl A, Alves RJE, Rittmann SKMR, Melcher $\mathrm{M}$, Leisch N, et al. Nitrososphaera viennensis gen. nov., sp. nov., an aerobic and mesophilic, ammonia-oxidizing archaeon from soil and a member of the archaeal phylum Thaumarchaeota. Int J Syst Evol Microbiol. 2014;64:2738-52.

17. Solioz M. Copper and bacteria: evolution, homeostasis and toxicity. Cham: Springer; 2018.

18. Villafane AA, Voskoboynik Y, Cuebas M, Ruhl I, Bini E. Response to excess copper in the hyperthermophile Sulfolobus solfataricus strain 98/2. Biochem Biophys Res Commun. 2009;385:67-71.

19. Ettema TJG, Brinkman AB, Lamers PP, Kornet NG, de Vos WM, van der Oost J. Molecular characterization of a conserved archaeal copper resistance (cop) gene cluster and its copper-responsive regulator in Sulfolobus solfataricus P2. Microbiology. 2006;152:1969-79.

20. Coombs JM, Barkay T. New findings on evolution of metal homeostasis genes: evidence from comparative genome analysis of bacteria and archaea. Appl Environ Microbiol. 2005;71:7083-91.

21. Lawton TJ, Kenney GE, Hurley JD, Rosenzweig AC. The CopC family: structural and bioinformatic insights into a diverse group 
of periplasmic copper binding proteins. Biochemistry. 2016;55:2278-90.

22. Rensing C, McDevitt SF. The copper metallome in prokaryotic cells. In: Metallomics and the cell. Dordrecht: Springer Netherlands; 2013.

23. Ladomersky E, Petris MJ. Copper tolerance and virulence in bacteria. Metallomics. 2015;7:957-64.

24. Zhang X-X, Rainey PB. Regulation of copper homeostasis in Pseudomonas fluorescens SBW25. Environ Microbiol. 2008;10:3284-94.

25. Amin SA, Moffett JW, Martens-Habbena W, Jacquot JE, Han Y, Devol A, et al. Copper requirements of the ammonia-oxidizing archaeon Nitrosopumilus maritimus SCM1 and implications for nitrification in the marine environment. Limnol Oceanogr. 2013;58:2037-45.

26. Qin W, Amin SA, Lundeen RA, Heal KR, Martens-Habbena W, Turkarslan S, et al. Stress response of a marine ammoniaoxidizing archaeon informs physiological status of environmental populations. ISME J. 2018;12:508-19.

27. Parkhurst DL. User's guide to PHREEQC, a computer program for speciation, reaction-path, advective-transport, and inverse geochemical calculations. Water-Resources Investigation Report; 1995.

28. Love MI, Huber W, Anders S. Moderated estimation of fold change and dispersion for RNA-seq data with DESeq2. Genome Biol. 2014;15:550.

29. Yasset P-R, Attila C, Bai J, Bernal-Linares M, Hewapathirana S, Kundu DJ, et al. The PRIDE database and related tools and resources in 2019: Improving support for quantification data. Nucleic Acids Res. 2019;47:D443-D450.

30. Esteves AM, Graça G, Peyriga L, Torcato IM, Borges N, Portais $\mathrm{J}-\mathrm{C}$, et al. Combined transcriptomics-metabolomics profiling of the heat shock response in the hyperthermophilic archaeon Pyrococcus furiosus. Extremophiles. 2019;23:101-18.

31. Coker JA, DasSarma P, Kumar J, Müller J, DasSarma S. Transcriptional profiling of the model Archaeon Halobacterium sp. NRC-1: responses to changes in salinity and temperature. Saline Syst. 2007;3:6.

32. Kosman DJ. Multicopper oxidases: a workshop on copper coordination chemistry, electron transfer, and metallophysiology. J Biol Inorg Chem. 2010;15:15-28.

33. Lawton TJ, Sayavedra-Soto LA, Arp DJ, Rosenzweig AC. Crystal structure of a two-domain multicopper oxidase: Implications for the evolution of multicopper blue proteins. J Biol Chem. 2009;284:10174-80.

34. Quintanar L, Stoj C, Taylor AB, Hart PJ, Kosman DJ, Solomon EI. Shall we dance? How a multicopper oxidase chooses its electron transfer partner. Acc Chem Res. 2007;40:445-52.

35. Prohaska JR. Impact of copper limitation on expression and function of multicopper oxidases (ferroxidases). Adv Nutr. 2011;2:89-95.

36. Cheng X, Xu N, Yu Q, Ding X, Qian K, Zhao Q, et al. Novel insight into the expression and function of the multicopper oxidases in Candida albicans. Microbiology. 2013;159:1044-55.

37. Taylor AB, Stoj CS, Ziegler L, Kosman DJ, Hart PJ. The copperiron connection in biology: structure of the metallo-oxidase Fet3p. Proc Natl Acad Sci. 2005;102:15459-64.

38. Singh SK, Grass G, Rensing C, Montfort WR. Cuprous oxidase activity of CueO from Escherichia coli. Society. 2004;186:7815-7.

39. Altschul S, de la Cruz F, Schaffer A, Zhang J, Zhang Z, Miller W, et al. Gapped BLAST and PSI-BLAST: a new generation of protein database search programs. Nucleic Acids Res. 1997;25:3389-402.

40. Altschul SF, Wootton JC, Gertz EM, Agarwala R, Morgulis A, Schäffer AA, et al. Protein database searches using compositionally adjusted substitution matrices. FEBS J. 2005;272:5101-9.
41. Vita N, Platsaki S, Baslé A, Allen SJ, Paterson NG, Crombie AT, et al. A four-helix bundle stores copper for methane oxidation. Nature. 2015;525:140-3.

42. Arnesano F, Banci L, Bertini I, Thompsett AR. Solution structure of CopC: a cupredoxin-like protein involved in copper homeostasis. Structure. 2002;10:1337-47.

43. Bayer B, Pelikan C, Bittner MJ, Reinthaler T, Könneke M, Herndl GJ, et al. Proteomic response of three marine ammonia-oxidizing archaea to hydrogen peroxide and their metabolic interactions with a heterotrophic alphaproteobacterium. mSystems 2019;4: e00181-19.

44. Mills SD, Jasalavich CA, Cooksey DA. A two-component regulatory system required for copper-inducible expression of the copper resistance operon of Pseudomonas syringae. J Bacteriol. 1993;175:1656-64.

45. Morosov X, Davoudi C-F, Baumgart M, Brocker M, Bott M. The copper-deprivation stimulon of Corynebacterium glutamicum comprises proteins for biogenesis of the actinobacterial cytochrome bc1-aa3 supercomplex. J Biol Chem. 2018;293:15628-40.

46. Hemp J, Gennis RB. Diversity of the heme-copper superfamily in archaea: insights from genomics and structural modeling. Bioenergetics. Berlin, Heidelberg: Springer; 2008. p. 1-31.

47. Sousa FL, Alves RJ, Ribeiro MA, Pereira-Leal JB, Teixeira M, Pereira MM. The superfamily of heme-copper oxygen reductases: Types and evolutionary considerations. Biochim Biophys Acta Bioenerg. 2012;1817:629-37.

48. Ekici S, Pawlik G, Lohmeyer E, Koch H-G, Daldal F. Biogenesis of cbb(3)-type cytochrome c oxidase in Rhodobacter capsulatus. Biochim Biophys Acta. 2012;1817:898-910.

49. Trasnea P-I, Andrei A, Marckmann D, Utz M, Khalfaoui-Hassani B, Selamoglu N, et al. A copper relay system involving two periplasmic chaperones drives cbb 3 -type cytochrome c oxidase biogenesis in Rhodobacter capsulatus. ACS Chem Biol. 2018;13:1388-97.

50. Dash BP, Alles M, Bundschuh FA, Richter OMH, Ludwig B. Protein chaperones mediating copper insertion into the $\mathrm{CuA}$ site of the aa3-type cytochrome c oxidase of Paracoccus denitrificans. Biochim Biophys Acta - Bioenerg. 2015;1847:202-11.

51. González-Guerrero M, Argüello JM. Mechanism of $\mathrm{Cu}+$-transporting ATPases: soluble $\mathrm{Cu}^{+}$chaperones directly transfer $\mathrm{Cu}^{+}$to transmembrane transport sites. Proc Natl Acad Sci USA. 2008;105:5992-7.

52. Tapio S, Yeh F, Shuman HA, Boos W. The malZ gene of Escherichia coli, a member of the maltose regulon, encodes a maltodextrin glucosidase. J Biol Chem. 1991;266:19450-8.

53. Osman D, Cavet JS. Bacterial metal-sensing proteins exemplified by ArsR-SmtB family repressors. Nat Prod Rep. 2010;27:668.

54. Gupta SD, Wu HC, Rick PDA. Salmonella typhimurium genetic locus which confers copper tolerance on copper-sensitive mutants of Escherichia coli. J Bacteriol. 1997;179:4977-84.

55. Cho S-H, Parsonage D, Thurston C, Dutton RJ, Poole LB, Collet $\mathrm{J}-\mathrm{F}$, et al. A new family of membrane electron transporters and its substrates, including a new cell envelope peroxiredoxin, reveal a broadened reductive capacity of the oxidative bacterial cell envelope. MBio. 2012;3:e0291-11.

56. Subedi P, Paxman JJ, Wang G, Ukuwela AA, Xiao Z, Heras B. The Scs disulfide reductase system cooperates with the metallochaperone CueP in Salmonella copper resistance. J Biol Chem. 2019. https://doi.org/10.1074/jbc.RA119.010164.

57. Karlsen OA, Larsen $\varnothing$, Jensen HB. The copper responding surfaceome of Methylococccus capsulatus Bath. FEMS Microbiol Lett. 2011;323:97-104.

58. Simon J, Klotz MG. Diversity and evolution of bioenergetic systems involved in microbial nitrogen compound transformations. Biochim Biophys Acta - Bioenerg. 2013;1827:114-35. 
59. Kozlowski JA, Stieglmeier M, Schleper C, Klotz MG, Stein LY. Pathways and key intermediates required for obligate aerobic ammonia-dependent chemolithotrophy in bacteria and Thaumarchaeota. ISME J. 2016;10:1836-45.

60. Spang A, Poehlein A, Offre P, Zumbrägel S, Haider S, Rychlik $\mathrm{N}$, et al. The genome of the ammonia-oxidizing candidatus nitrososphaera gargensis: Insights into metabolic versatility and environmental adaptations. Environ Microbiol. 2012;14: 3122-45.

61. Chain Patrick, Lamerdin J, Larimer F, Regala W, Lao V, Land M, et al. Complete genome sequence of the ammonia-oxidizing bacterium and obligate chemolithoautotroph Nitrosomonas europaea. J Bacteriol. 2003;185:2759-73.

62. Berube PM, Stahl DA. The divergent amoc3 subunit of ammonia monooxygenase functions as part of a stress response system in Nitrosomonas europaea. J Bacteriol. 2012;194:3448-56.

63. Offre P, Kerou M, Spang A, Schleper C. Variability of the transporter gene complement in ammonia-oxidizing archaea. Trends Microbiol. 2014;22:665-75.

64. Nakagawa T, Stahl DA. Transcriptional response of the archaeal ammonia oxidizer Nitrosopumilus maritimus to low and environmentally relevant ammonia concentrations. Appl Environ Microbiol. 2013;79:6911-6.

65. Friedrich T, Scheide D. The respiratory complex I of bacteria, archaea and eukarya and its module common with membranebound multisubunit hydrogenases. FEBS Lett. 2000;479:1-5.

66. Bräsen C, Esser D, Rauch B, Siebers B. Carbohydrate metabolism in Archaea: current insights into unusual enzymes and pathways and their regulation. Microbiol Mol Biol Rev. 2014;78:89-175.

67. Sauvé S, McBride MB, Norvell WA, Hendershot WH. Copper solubility and speciation of in situ contaminated soils: effects of copper level, $\mathrm{pH}$ and organic matter. Water Air Soil Pollut. 1997;100:133-49.

68. Gledhill M, Nimmo M, Hill SJ, Brown MT. The toxicity of copper (II) species to marine algae, with particular reference to macroalgae. J Phycol. 1997;33:2-11.
69. Maurer F, Christl I, Fulda B, Voegelin A, Kretzschmar R. Copper redox transformation and complexation by reduced and oxidized soil humic acid. 2 Potentiometric titrations dialysis cell. Exp Environ Sci Technol. 2013;47:10912-21.

70. Fulda B, Voegelin A, Maurer F, Christl I, Kretzschmar R. Copper redox transformation and complexation by reduced and oxidized soil humic acid. 1. X-ray absorption spectroscopy study. Environ Sci Technol. 2013;47:10903-11.

71. Logan EM, Pulford ID, Cook GT, McKenzie AB. Complexation of $\mathrm{Cu}^{2+}$ and $\mathrm{Pb}^{2+}$ by peat and humic acid. Eur J Soil Sci. 1997;48:685-96.

72. Minnich MM, McBride MB. Copper activity in soil solution: I. measurement by ion-selective electrode and donnan dialysis1. Soil Sci Soc Am J. 1987;51:568.

73. Pendias AK. Elements of group 11: previously group Ib. In: Pendias AK, editor. Trace elements in soils and plants, 4th ed. Boca Raton: CRC Press Taylor and Francis Group; 2010. p. 584.

74. Jenkins SN, Murphy DV, Waite IS, Rushton SP, O'Donnell AG. Ancient landscapes and the relationship with microbial nitrification. Sci Rep. 2016;6:30733.

75. Moffett JW, Zika RG. Measurement of copper(I) in surface waters of the subtropical Atlantic and Gulf of Mexico. Geochim Cosmochim Acta. 1988;52:1849-57.

76. Buerge-Weirich $\mathrm{D}$, Sulzberger B. Formation of $\mathrm{Cu}(\mathrm{I})$ in estuarine and marine waters: application of a new solid-phase extraction method to measure $\mathrm{Cu}(\mathrm{I})$. Environ Sci Technol. 2004;38:1843-8.

77. Whitby H, Hollibaugh JT, van den Berg CMG. Chemical speciation of copper in a salt marsh estuary and bioavailability to Thaumarchaeota. Front Mar Sci. 2017;4:178.

78. Jacquot JE, Horak REA, Amin SA, Devol AH, Ingalls AE, Armbrust EV, et al. Assessment of the potential for copper limitation of ammonia oxidation by Archaea in a dynamic estuary. Mar Chem. 2014;162:37-49.

79. Tang D, Warnken KW, Santschi PH. Organic complexation of copper in surface waters of Galveston Bay. Limnol Oceanogr. 2001;46:321-30. 